Article

\title{
Up-Concentration of Chromium in Stainless Steel Slag and Ferrochromium Slags by Magnetic and Gravity Separation
}

\author{
Frantisek Kukurugya *(D), Peter Nielsen $(\mathbb{D})$ and Liesbeth Horckmans ${ }^{(\mathbb{C}}$ \\ Vlaamse Instelling Voor Technologisch Onderzoek (VITO), 2400 Mol, Belgium; peter.nielsen@vito.be (P.N.); \\ liesbeth.horckmans@vito.be (L.H.) \\ * Correspondence: fero.kukurugya@vito.be
}

Received: 31 August 2020; Accepted: 9 October 2020; Published: 12 October 2020

\begin{abstract}
Slags coming from stainless steel (SS) and ferrochromium ( $\mathrm{FeCr}$ ) production generally contain between 1 and $10 \% \mathrm{Cr}$, mostly present in entrapped metallic particles ( $\mathrm{Fe}-\mathrm{Cr}$ alloys) and in spinel structures. To recover $\mathrm{Cr}$ from these slags, magnetic and gravity separation techniques were tested for up-concentrating $\mathrm{Cr}$ in a fraction for further processing. In case of $\mathrm{SS}$ slag and low carbon (LC) $\mathrm{FeCr}$ slag a wet high intensity magnetic separation can up-concentrate $\mathrm{Cr}$ in the SS slag (fraction $<150 \mu \mathrm{m}$ ) from $2.3 \mathrm{wt} . \%$ to almost $9 \mathrm{wt} . \%$ with a yield of $7 \mathrm{wt} . \%$, and in the LC FeCr slag from $3.1 \mathrm{wt} . \%$ to $11 \mathrm{wt} . \%$ with a yield of $3 \mathrm{wt} . \%$. Different behavior of Cr-containing spinel's in the two slag types observed during magnetic separation can be explained by the presence or absence of Fe in the lattice of the Cr-containing spinel's, which affects their magnetic susceptibility. The Cr content of the concentrates is low compared to chromium ores, indicating that additional processing steps are necessary for a recovery process. In the case of high carbon (HC) $\mathrm{FeCr}$ slag, a $\mathrm{Cr}$ up-concentration by a factor of more than three (from $9 \mathrm{wt} . \%$ to $28 \mathrm{wt} . \%$ ) can be achieved on the as received slag, after a single dry low intensity magnetic separation step, due to the well-liberated $\mathrm{Cr}$-rich compounds present in this slag. After gravity separation of the $\mathrm{HC} \mathrm{FeCr} \mathrm{slag,} \mathrm{a} \mathrm{fraction} \mathrm{with} \mathrm{a} \mathrm{Cr}$ content close to high grade $\mathrm{Cr}$ ores $\left(\geq 50 \% \mathrm{Cr}_{2} \mathrm{O}_{3}\right)$ can be obtained. This fraction represents $12 \mathrm{wt} . \%$ of the $\mathrm{HC} \mathrm{FeCr}$ slag, and can probably be used directly in traditional smelting processes.
\end{abstract}

Keywords: stainless steel slag; ferrochromium slag; magnetic separation; gravity separation

\section{Introduction}

In 2018, 50.7 Mt of stainless steel (SS) was produced globally, with an average annual growth of $5.8 \%$ since 1950 [1]. It is estimated that approximately 0.3 tons of slag per ton of SS is produced as a by-product [2]; thus, about $17 \mathrm{Mt}$ of SS slag is produced annually. In case of FeCr production, the amount of generated slag depends on the type of produced FeCr. During high-carbon (HC) $\mathrm{FeCr}$ production, 1.1-1.6 tons of slag per ton of $\mathrm{HC} \mathrm{FeCr}$ is produced with a global annual production of $13 \mathrm{Mt} \mathrm{HC} \mathrm{FeCr}$ in 2018; this implies an annual production of about $17 \mathrm{Mt}$ of $\mathrm{HC} \mathrm{FeCr}$ slag. In the case of low-carbon (LC) FeCr, the amount of produced slag per ton of $\mathrm{LC} \mathrm{FeCr}$ is 2.4-2.5 tons with a global annual production $0.9 \mathrm{Mt}$ in 2018 [3], which corresponds to $2.2 \mathrm{Mt}$ of LC FeCr slag.

Although, a significant part of the SS and $\mathrm{FeCr}$ slags produced in Europe are being valorized mainly in the construction industry (road construction, addition in cement and concrete, etc.) $[4,5]$, the relatively high $\mathrm{Cr}$ content in these slags (1-10 wt.\%) [3,6,7] represent a serious obstacle in their full valorization.

In slags from stainless steel and $\mathrm{FeCr}$ production, $\mathrm{Cr}$ is mostly present in the form of stable spinels, as $\mathrm{Cr}(\mathrm{III})$, which is a non-toxic, non-hazardous, essential trace element [8]. However, there is a risk of 
possible oxidation of $\mathrm{Cr}(\mathrm{III})$ to $\mathrm{Cr}(\mathrm{VI})$ [9], which present a serious concern for human health and the environment [8].

Moreover, $\mathrm{Cr}$ is an element with high economic importance for the EU economy [10] and SS and $\mathrm{FeCr}$ slags could be considered secondary raw materials for the recovery of $\mathrm{Cr}$ and other valuable elements (e.g., $\mathrm{V}, \mathrm{Nb}$, and Mo).

Production of SS and other metal alloys accounts for approximately $85 \%$ of Cr consumption [11]. In case of $\mathrm{SS}$ production, $\mathrm{Cr}$ is added as $\mathrm{FeCr}$, which dependent on carbon content can be classified as high-carbon (HC) FeCr (2-12\% C), medium-carbon (MC) FeCr (0.5-4\% C), and low-carbon (LC) FeCr $(0.01-0.5 \%$ C) [12].

$\mathrm{HC} \mathrm{FeCr}$ is produced mainly by direct carbothermic reduction of chromite ore in submerged arc furnaces (SAF), while MC FeCr can be produced by the silicothermic reduction of chromite ores and concentrates, or by the decarburization of $\mathrm{HC} \mathrm{FeCr}$ in an oxygen-blow converter. In the European union, $\mathrm{LC} \mathrm{FeCr}$ is produced by the Duplex process, which is based on silicothermic reduction of a lime-chromite slag in a tiltable AC arc furnace with Søderberg electrodes [12].

Commercial chromite ores used in $\mathrm{FeCr}$ production can be classified based on $\mathrm{Cr}_{2} \mathrm{O}_{3}$ content as low grade (25-38 wt. $\% \mathrm{Cr}_{2} \mathrm{O}_{3}$ ), medium grade (38-50 wt. $\% \mathrm{Cr}_{2} \mathrm{O}_{3}$ ), and high grade (>50 wt.\% $\mathrm{Cr}_{2} \mathrm{O}_{3}$ ). To use a chromite ore directly as an input for smelting $\mathrm{FeCr}$, the ore generally needs to contain more than 49 wt. $\% \mathrm{Cr}_{2} \mathrm{O}_{3}$. Chromite ores with $\mathrm{Cr}_{2} \mathrm{O}_{3}$ content lower than 49 wt. $\%$ need to be further up-concentrated by mineral processing techniques (e.g., magnetic separation, gravity separation, flotation, etc.) [13].

Considering the depletion of high-grade $\mathrm{Cr}$ ores and the increasing global demand for SS and $\mathrm{FeCr}$, attention also needs to be paid to recovery of $\mathrm{Cr}$ from secondary raw materials. It is evident that, in order to make $\mathrm{Cr}$ recovery from $\mathrm{SS}$ and $\mathrm{FeCr}$ slags by traditional smelting/pyrometallurgical processes economically interesting, the $\mathrm{Cr}$ content needs to be increased substantially. This could be achieved by applying mineral processing technologies like magnetic and gravity separation. Several studies dealing with physical separation techniques for up-concentration of $\mathrm{Cr}$ from primary $\mathrm{Cr}$ ores have been published in the last decade [14-17].

As the physical and chemical properties of secondary raw materials (e.g., Cr-containing slags) often differ from those of primary $\mathrm{Cr}$-ores, technological solutions used for primary $\mathrm{Cr}$ ores need to be adapted for treating these secondary raw materials. For instance, in $\mathrm{SS}$ and $\mathrm{FeCr}$ slags, small $\mathrm{Cr}$-rich grains (often 10-100 $\mu \mathrm{m}$ ) are enclosed in the matrix minerals [3] and to liberate them an additional comminution step needs to be included prior to the separation. By comminution, fine-grained material (often $<500 \mu \mathrm{m}$ ) is produced which present a serious challenge for physical separation techniques. This is not the case for primary ores, where grain sizes of $0-15 \mathrm{~mm}$ are separated and used in $\mathrm{FeCr}$ production [13]. Moreover, $\mathrm{Cr}$ in chromite ore is mostly present as $\mathrm{Fe}-\mathrm{Cr}$ spinel, while the spinels present in SS and LC FeCr slag contain no, or very little, Fe. In the SS and LC FeCr slags the main spinel phase is $\mathrm{MgCr}_{2} \mathrm{O}_{4}$ [3].

The main aim of this study was to investigate the potential of magnetic and gravity separation techniques for up-concentration of $\mathrm{Cr}$ present in $\mathrm{SS}$ and $\mathrm{FeCr}$ slags mainly as $\mathrm{Cr}$-containing spinel and $\mathrm{Fe}-\mathrm{Cr}$ alloy. Up-concentration of $\mathrm{Cr}$ by using physical separation could improve both the feasibility of subsequent $\mathrm{Cr}$ recovery processes and facilitate the valorization of the $\mathrm{Cr}$-depleted fractions.

\section{Materials and Methods}

\subsection{Materials}

SS slag, delivered by slag treatment plant from Belgium and two types of $\mathrm{FeCr}$ slags coming from European FeCr producers, were studied. Representative samples of LC FeCr and $\mathrm{HC}$ FeCr slags were delivered as size fractions 4-9 $\mathrm{mm}$ and 0-6 $\mathrm{mm}$, respectively. The SS slag is an end product after metal recovery and was delivered as a fine powder $(\mathrm{D} 90=150 \mu \mathrm{m})$. 


\subsection{Methods}

\subsubsection{Characterization of the Samples}

Representative subsamples were taken from all three slag samples. These subsamples were dried to constant weight at $40{ }^{\circ} \mathrm{C}$. After drying, the samples were crushed, milled, and sieved. Fractions $<125 \mu \mathrm{m}$ were used for chemical and mineralogical analysis.

Chemical analyses of the starting materials were performed by a high performance energy dispersive X-ray fluorescence spectrometer (EDXRF) with polarized X-ray excitation geometry (HE XEPOS, Spectro Analytical Systems, Kleve, Germany). The instrument was equipped with a $50 \mathrm{~W}$ tungsten end window tube (maximum $60 \mathrm{kV}, 2 \mathrm{~mA}$ ) and a Silicon Drift Detector. For signal optimization different targets were applied. All analysis was performed under helium atmosphere. Dried and finely ground $(<125 \mu \mathrm{m})$ samples were analyzed as fused beads. The quantification was performed using a pre-calibrated software package for the quantitative analysis of geological fused beads.

In addition to EDXRF, a handheld XRF analyzer (Niton XL3t GOLDD+, ThermoFisher Scientific, Madison, WI, USA) placed in a mobile test stand, was used for fast elemental analysis of intermediate and final fractions produced by magnetic or gravity separation. The XRF analyzer is equipped with a $\mathrm{Ag}$ anode $(50 \mathrm{kV}$ and $0.2 \mathrm{~mA})$. Measuring time was $120 \mathrm{~s}$ for every measurement. This XRF analyzer was chosen for the analysis based on initial comparison with ICP-OES, EDXRF (powder) and EDXRF (fused bead) where it gave comparable values for $\mathrm{Cr}$ and $\mathrm{Fe}$ in particular.

Mineralogy was determined by X-ray powder diffraction (XRD), carried out with a PANalytical Empyrean system (PANalytical B.V., Almelo, the Netherlands), operated at $40 \mathrm{kV}$ and $45 \mathrm{~mA}$, with Co tube (fine focus, wavelength $=1.7903 \AA$ ). Continuous scans with a step size rate of $0.013^{\circ} / 49.725 \mathrm{~s}$ were performed in a $2 \theta$ range of 5 to $120^{\circ}$ (2D-detector). The obtained diffractograms were qualitatively analyzed with the aid of HighScore Plus software (version 4.6a).

For SEM-EDS analysis, the samples were embedded in a low-viscosity epoxy resin and gradually polished down to $\frac{1}{4} \mu \mathrm{m}$ diamond powder grit size. The samples were coated with $\mathrm{Pt}-\mathrm{Pd}$ prior to microscopic analysis. Morphological observations were carried out by a SEM microscope FEI NOVA NANOSEM 450 (Brno, Czech Republic) with EDX analyzer BRUKER QUANTAX 200 (Berlin, Germany) with SDD detector.

\subsubsection{Sample Preparation}

In cases when crushing and/or milling were applied as pre-treatment methods, a laboratory jaw crusher (Model BB200, Retsch, Germany) and planetary ball mill (Model PM400, Retsch, Germany) were used. Sieving was carried out using a vibratory sieve shaker (Model AS200, Retsch, Germany).

\subsubsection{Magnetic Separation}

Several magnetic separation techniques were employed in order to up-concentrate $\mathrm{Cr}$-rich phases present in SS and $\mathrm{FeCr}$ slags. Based on preliminary experiments, the most suitable magnetic separation techniques were selected for a certain slag. All the magnetic separation equipment was delivered by Master Magnets Ltd. Tested magnetic separation techniques and their allocations to slag materials (including particle size) are listed in Table 1.

LIMS/HIMS (Supplementary Materials, Figure S1a) was carried out by spreading a dry sample of ca. $200 \mathrm{~g}$ in a thin layer on a flat surface. The permanent magnet (ferrite or REE(Rare-earth elements) was covered with a plastic bag for convenient removal of the magnetic fraction. After the separation magnetic and non-magnetic fractions were analyzed by XRF. 
Table 1. Magnetic separation techniques tested in this study.

\begin{tabular}{|c|c|c|c|}
\hline Abbreviation & Description (Type) & $\begin{array}{l}\text { Magnetic Field } \\
\text { Strength (Tesla) }\end{array}$ & $\begin{array}{l}\text { Tested Material } \\
\text { (Size Fraction) }\end{array}$ \\
\hline LIMS & $\begin{array}{l}\text { Dry low intensity magnetic separation } \\
\text { (Handheld ferrite magnet) }\end{array}$ & 0.15 & $\begin{array}{l}\mathrm{HC}^{1} \mathrm{FeCr} \text { slag } \\
\quad(0.5-4 \mathrm{~mm})\end{array}$ \\
\hline HIMS & $\begin{array}{l}\text { Dry high intensity magnetic separation } \\
\text { (Handheld REE }{ }^{2} \text { magnet) }\end{array}$ & 1 & $\begin{array}{c}\mathrm{LC}^{1} \mathrm{FeCr} \text { slag } \\
(0.125-0.5 \mathrm{~mm}) \\
\mathrm{HC} \text { FeCr slag } \\
(0.5-4 \mathrm{~mm})\end{array}$ \\
\hline WLIMS & $\begin{array}{l}\text { Wet low intensity magnetic separation } \\
\text { (Wetchute with ferrite magnet) }\end{array}$ & 0.15 & $\begin{array}{c}\text { HC FeCr slag } \\
(<0.5 \mathrm{~mm})\end{array}$ \\
\hline WHIMS & $\begin{array}{l}\text { Wet high intensity magnetic separation } \\
\text { (Wetchute with REE magnet) }\end{array}$ & 0.8 & $\begin{array}{c}\mathrm{SS}^{1} \text { slag }(<0.15 \mathrm{~mm}) \\
\text { HC FeCr slag } \\
(<0.5 \mathrm{~mm})\end{array}$ \\
\hline WHIMSe & $\begin{array}{l}\text { Wet high gradient/intensity magnetic } \\
\text { separation (WHIMS 500) }\end{array}$ & $0-2$ & $\begin{array}{c}\text { SS slag }(<0.15 \mathrm{~mm}) \\
\text { LC FeCr slag } \\
(<0.125 \mathrm{~mm})\end{array}$ \\
\hline
\end{tabular}

WLIMS/WHIMS were carried out on a wetchute (Supplementary Materials, Figure S1b) with a permanent magnet (ferrite or REE). A sample of $10 \mathrm{~g}$ was mixed with $500 \mathrm{~mL}$ water (L:S ratio $=50$ ), and the suspension was fed at the top of the wetchute. The magnetic fraction stayed on the wetchute, while the non-magnetic fraction was washed out. Additional washing of the magnetic fraction with $500 \mathrm{~mL}$ of distilled water was carried out to clean the magnetic fraction. Resulting fractions were dried for $24 \mathrm{~h}$ at $40^{\circ} \mathrm{C}$ before milling $(<125 \mu \mathrm{m})$ and XRF analysis.

WHIMSe experiments were carried out using WHIMSe separator (Supplementary Materials, Figure S1c). Steel wool was used as a separation matrix. The purpose of the steel wool in the WHIMSe is to hold magnetic (ferro- and paramagnetic) materials in the magnetic field while diamagnetic (non-magnetic) particles are being washed out. The magnetic field in WHIMSe can be adjusted from 0 to $2 \mathrm{~T}$ by adjusting the electric current $(0-17.5 \mathrm{~A})$ in the coils. As it is difficult to measure the exact magnetic field strength when steel wool is used as a matrix, in this paper the WHIMSe set-up is reported in Amperes. An indicative relation between the electric current (in Amperes) and the magnetic field (in Gauss), provided by the equipment manufacturer, can be found in Supplementary information (Supplementary Materials, Figure S2). The material was first fed into the WHIMSe at the maximum current of $17.5 \mathrm{~A}$ and the non-magnetic fraction was washed out. The magnetic fraction was recovered by turning off the magnetic field and washing with water. All output fractions were dried for $24 \mathrm{~h}$ at $40^{\circ} \mathrm{C}$ before XRF analysis.

In order to optimize WHIMSe for $\mathrm{Cr}$ up-concentration, sequential experiments were carried out by gradually decreasing the electric current. In this case, after washing out the non-magnetic fraction at the highest current (17.5 A), the current was sequentially reduced to 15, 10, 5, 1, and $0 \mathrm{~A}$, and the non-magnetic fraction was washed out at every step. The final fractions were dried for $24 \mathrm{~h}$ at $40^{\circ} \mathrm{C}$ and analyzed by XRF.

\subsubsection{Gravity Separation}

The gravity separation test was carried out using a Holman-Wilfley wet shaking table (WST). The test was performed only for $\mathrm{HC}$ FeCr slag, fraction 1-2 mm. Approximately $360 \mathrm{~g}$ of the sample was used for the test. Conditions used during WST separation are listed in Table 2. 
Table 2. Conditions for wet shaking table (WST) separation of HC FeCr slag (fraction 1-2 mm).

\begin{tabular}{ccc}
\hline Parameter & Value & Unit \\
\hline stroke speed & 250 & $\mathrm{rpm}$ \\
washing water flow & 1000 & $\mathrm{~L} / \mathrm{h}$ \\
feed dilution water & 250 & $\mathrm{~L} / \mathrm{h}$ \\
\hline
\end{tabular}

The final output fractions were dried for $24 \mathrm{~h}$ at $40^{\circ} \mathrm{C}$, milled $(<125 \mu \mathrm{m})$ and analyzed by XRF. The WST, with the indication of outputs for different fractions (fraction $1=$ the lightest; fraction $5=$ the heaviest), are shown in Supplementary Materials, Figure S3.

\section{Results}

\subsection{Characterization of the Samples}

Table 3 shows the chemical composition of the studied slags analyzed by EDXRF.

Table 3. Chemical composition of the studied slags.

\begin{tabular}{ccccc}
\hline Element/Oxide & Units & SS Slag & LC FeCr Slag & HC FeCr Slag $^{2}$ \\
\hline $\mathrm{Al}_{2} \mathrm{O}_{3}$ & wt. $\%$ & $4.2 \pm 0.5$ & $7.2 \pm 0.6$ & 17.9 \\
$\mathrm{CaO}$ & wt. $\%$ & $45.1 \pm 2.6$ & $43.0 \pm 2.9$ & 2.5 \\
$\mathrm{Fe}_{\text {tot. }}$ & wt. $\%$ & $0.6 \pm 0.1$ & $0.3 \pm 0.1$ & 6.4 \\
$\mathrm{MgO}$ & wt. $\%$ & $11.0 \pm 1.8$ & $14.0 \pm 1.8$ & 15.8 \\
$\mathrm{MnO}$ & wt. $\%$ & $1.1 \pm 0.2$ & $0.1 \pm 0.01$ & 0.2 \\
$\mathrm{SiO}_{2}$ & wt. $\%$ & $30.8 \pm 5.6$ & $30.3 \pm 2.9$ & 29.1 \\
$\mathrm{~V}_{2} \mathrm{O}_{5}$ & wt. $\%$ & $0.09 \pm 0.03$ & $0.06 \pm 0.02$ & 0.09 \\
$\mathrm{Cr}$ & wt. $\%$ & $2.3 \pm 0.5$ & $3.2 \pm 0.4$ & 11.5 \\
$\mathrm{Mo}$ & $\mathrm{mg} / \mathrm{kg}$ & $40^{1}$ & $<5$ & $<5$ \\
$\mathrm{Nb}$ & $\mathrm{mg} / \mathrm{kg}$ & $617^{1}$ & $<5$ & $<5$ \\
\hline
\end{tabular}

The main phases identified in the SS slag by XRD analysis were: $\mathrm{Ca}-(\mathrm{Mg}-\mathrm{Al}-)$ silicates (merwinite, bredigite, akermanite, cuspidine, and dicalcium silicate), calcite, periclase, and spinel $\left(\mathrm{MgCr}_{2} \mathrm{O}_{4}\right)$. Significant differences in chemical composition (Table 3) and mineralogy between LC FeCr slag and $\mathrm{HC} \mathrm{FeCr}$ slag were observed. In the case of $\mathrm{LC} \mathrm{FeCr}$ production, reduction with silicon proceeds in the presence of lime, which results in a significantly higher $\mathrm{CaO}$ content of the $\mathrm{LC} \mathrm{FeCr} \mathrm{slag} \mathrm{(present}$ mainly as bredigite and merwinite minerals in the slag). In the case of $\mathrm{HC} \mathrm{FeCr} \mathrm{slag,} \mathrm{also} \mathrm{metallic}$ $\mathrm{Fe}-\mathrm{Cr}$ grains were identified. The reason for the presence of $\mathrm{Fe}-\mathrm{Cr}$ particles might be that in $\mathrm{HC} \mathrm{FeCr}$ production, after carbothermal reduction in SAF, molten metal and slag are tapped off through the same tap holes using cascade tapping into the same metal vessel [12].

As can be seen from SEM-EDS analysis, the matrix of the SS slag consists of Ca-silicates and Ca-Mg-Al-silicates (Figure 1a). Cr-spinel phases can be clearly identified, showing a potential for physical separation. However, due to the small dimensions of the $\mathrm{Cr}$-rich particles, full liberation would require additional milling.

The SEM-EDS analysis of LC FeCr slag (Figure 1b) shows elongate grains of Ca-silicates in between which veins of spinels are present. Small $(20-40 \mu \mathrm{m})$ metallic FeCr particles are spread out diffusely over the material. As shown in Figure 1b, some of them are encapsulated in the Ca-silicate matrix. In the case of $\mathrm{HC} \mathrm{FeCr}$ slag (Figure 1c), Cr-rich grains (mostly as FeCr particles) and Ca-silicates grains are already very well liberated indicating potential for their separation. Observation of the SEM analysis are well aligned with the results of mineral liberation analysis (MLA) published in our recent study [3]. 

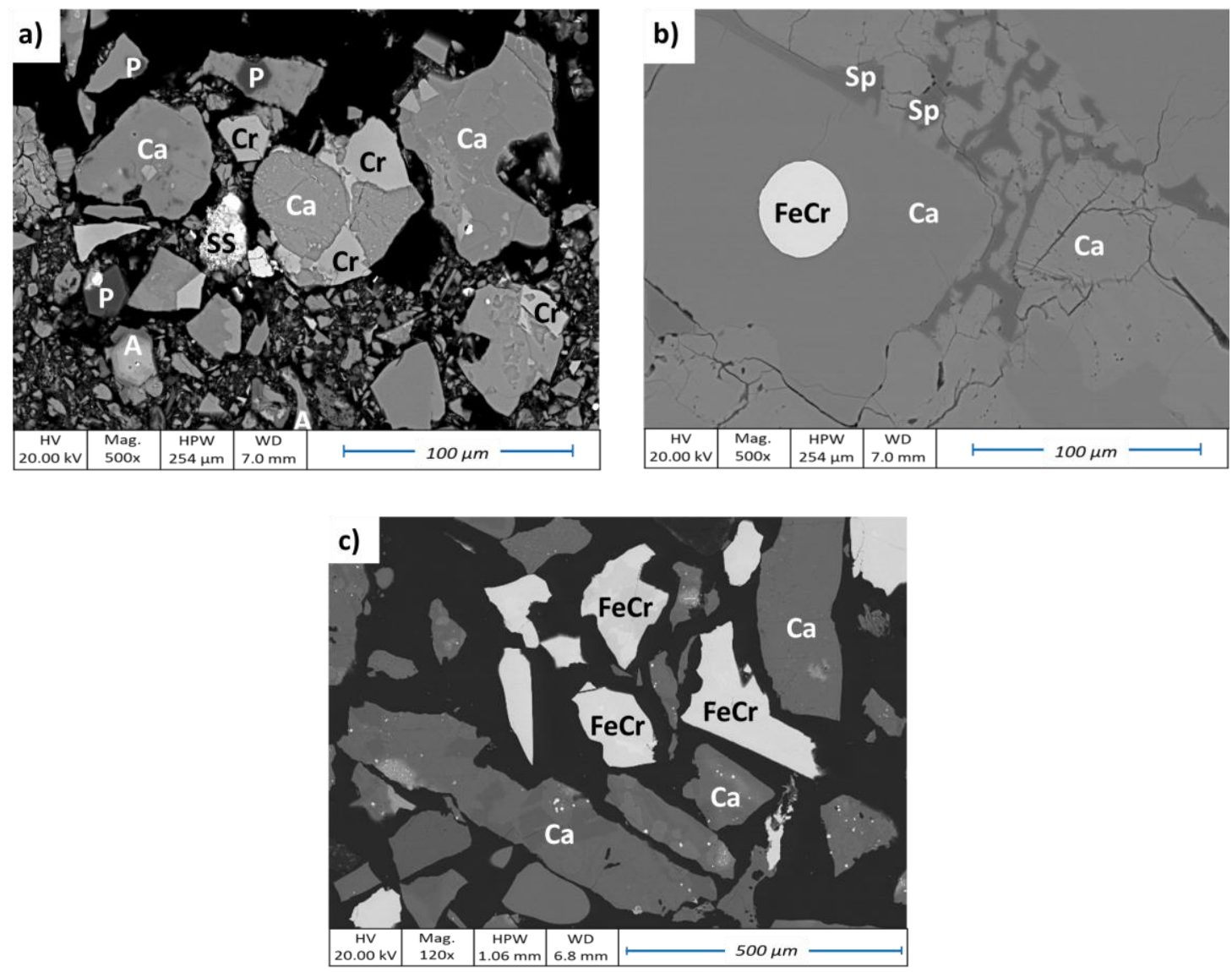

Figure 1. SEM-Backscattered Electron (BSE) images of (a) SS slag,(b) LC FeCr slags and (c) HC FeCr slag. $\mathrm{SS}=$ stainless steel, $\mathrm{Ca}=\mathrm{Ca}$ - silicates, $\mathrm{A}=\mathrm{CaMgAl}$-silicates, $\mathrm{Cr}=\mathrm{Cr}$-rich spinel phase, $\mathrm{P}=$ Periclase, $\mathrm{Sp}=$ spinel, $\mathrm{FeCr}=$ Ferrochrome particle. Phase identifications are based on SEM-EDS analysis.

\subsection{Results of Magnetic Separation}

\subsubsection{Magnetic Separation-SS Slag}

A combination of WHIMS and WHIMSe was used to process SS slag. The final flowsheet, including chemical compositions of input, intermediate and final fractions, is shown in Figure 2. The SS slag, as received $\left(D_{90}=150 \mu \mathrm{m}\right)$, was treated by WHIMS, after which the magnetic fraction was further purified by a second WHIMS separation step and the non-magnetic fraction was processed by a single WHIMSe separation step (at 17.5 A). Three output fractions (M2, NM2+M3, and NM4) with different $\mathrm{Cr}$ contents were obtained. The $\mathrm{Cr}$-rich fraction (M2) contains $8.8 \% \mathrm{Cr}$, which represents an increase by almost a factor 4 . The weight yield of the $\mathrm{Cr}$-rich fraction was $7 \%$ representing $31 \%$ of $\mathrm{Cr}$ recovery. As expected, Fe was up-concentrated in the M2 fraction together with $\mathrm{Cr}$. Up-concentration of Mn in the same fraction indicates presence of Mn-Cr spinels.

During sequential WHIMSe separation, similar $\mathrm{Cr}$ up-concentration (but also $\mathrm{V}$ and $\mathrm{Nb}$ ) can be observed. As shown in Figure 3, the $\mathrm{Cr}$ content in the magnetic fractions increases with decreasing magnetic field, indicating than $\mathrm{Cr}$-rich particles are those with the highest magnetic susceptibility. The highest $\mathrm{Cr}$ content $(8.3 \mathrm{wt} . \%)$ was measured in the final magnetic fraction washed out at the lowest magnetic field (current $0 \mathrm{~A}$ ). In this case the weight yield was $5 \%$ representing $21 \% \mathrm{Cr}$ recovery in this fraction. On the other hand, the fraction washed out at the highest magnetic field (at 17.5 A), with a weight yield of $73 \%$, contains only $0.7 \mathrm{wt} . \% \mathrm{Cr}$, and thus only $22 \%$ of the initial $\mathrm{Cr}$. These results indicate that by performing a single WHIMSe separation at $17.5 \mathrm{~A}$, the majority of the $\mathrm{Cr}$ can be removed from the matrix (non-magnetic) material. 


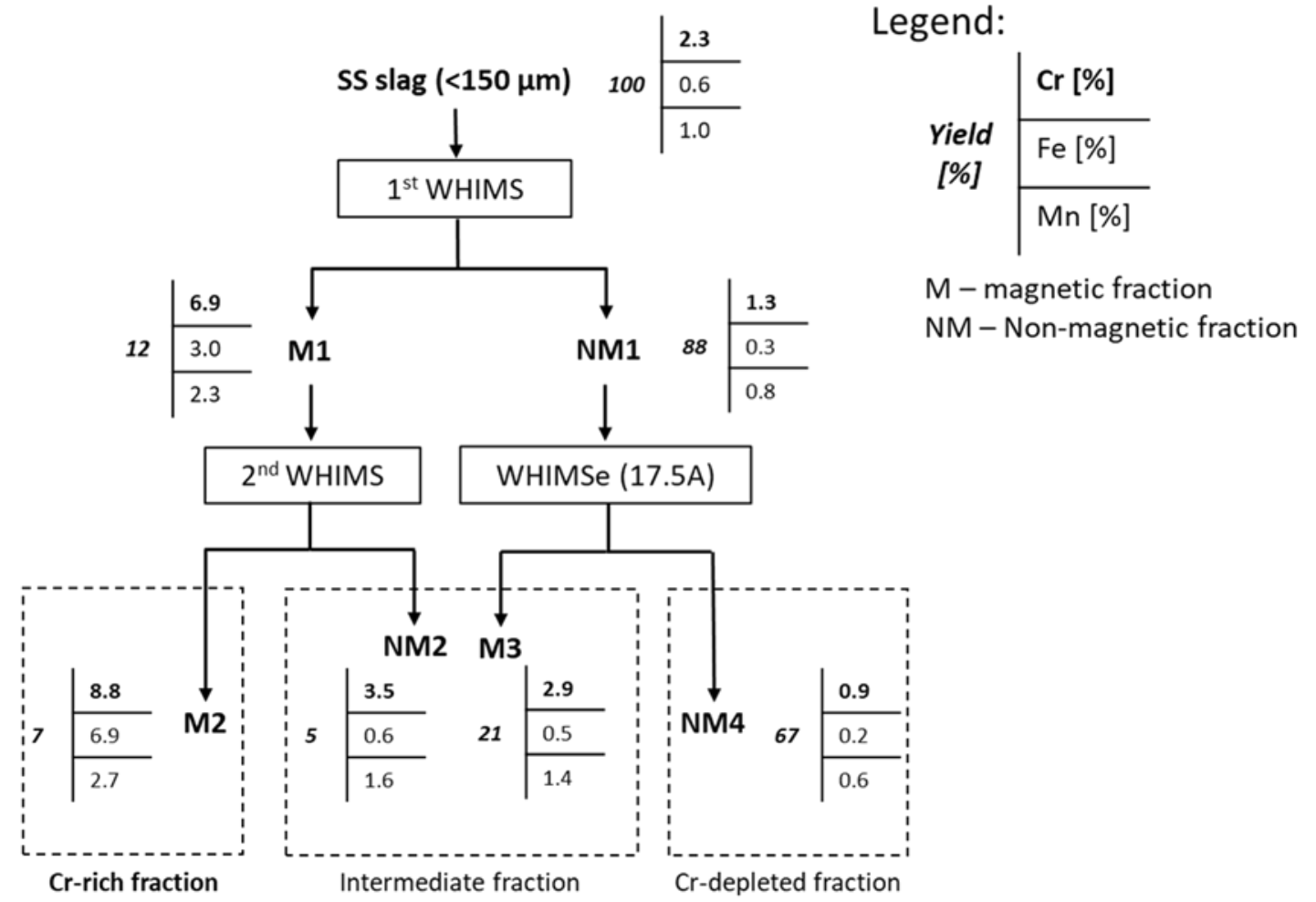

Figure 2. Processing of SS slag by combination of WHIMS and WHIMSe.

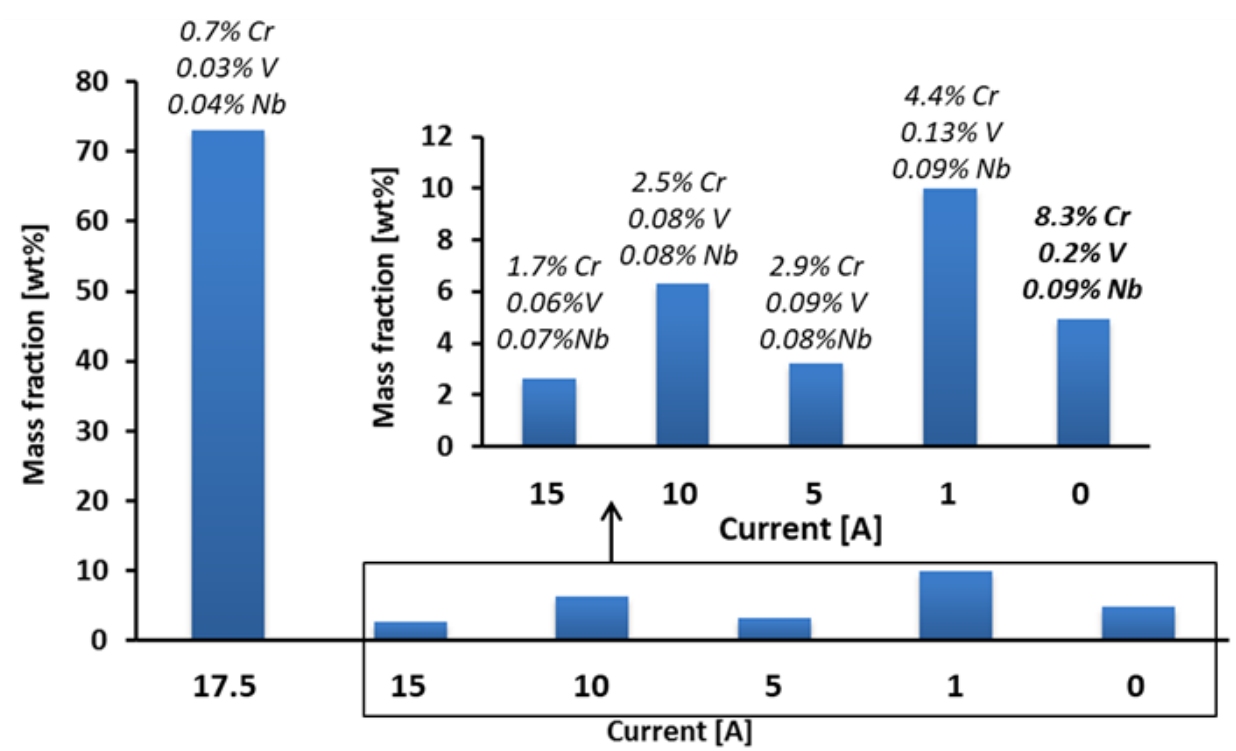

Figure 3. Results of the sequential WHIMSe separation for SS slag.

\subsubsection{Magnetic Separation-LC FeCr Slag}

A combination of HIMS and WHIMSe was employed to process LC FeCr slag (size fraction $<500 \mu \mathrm{m}$ ). The process flow with the mass balance and chemical composition of the different streams are shown in Figure 4. 


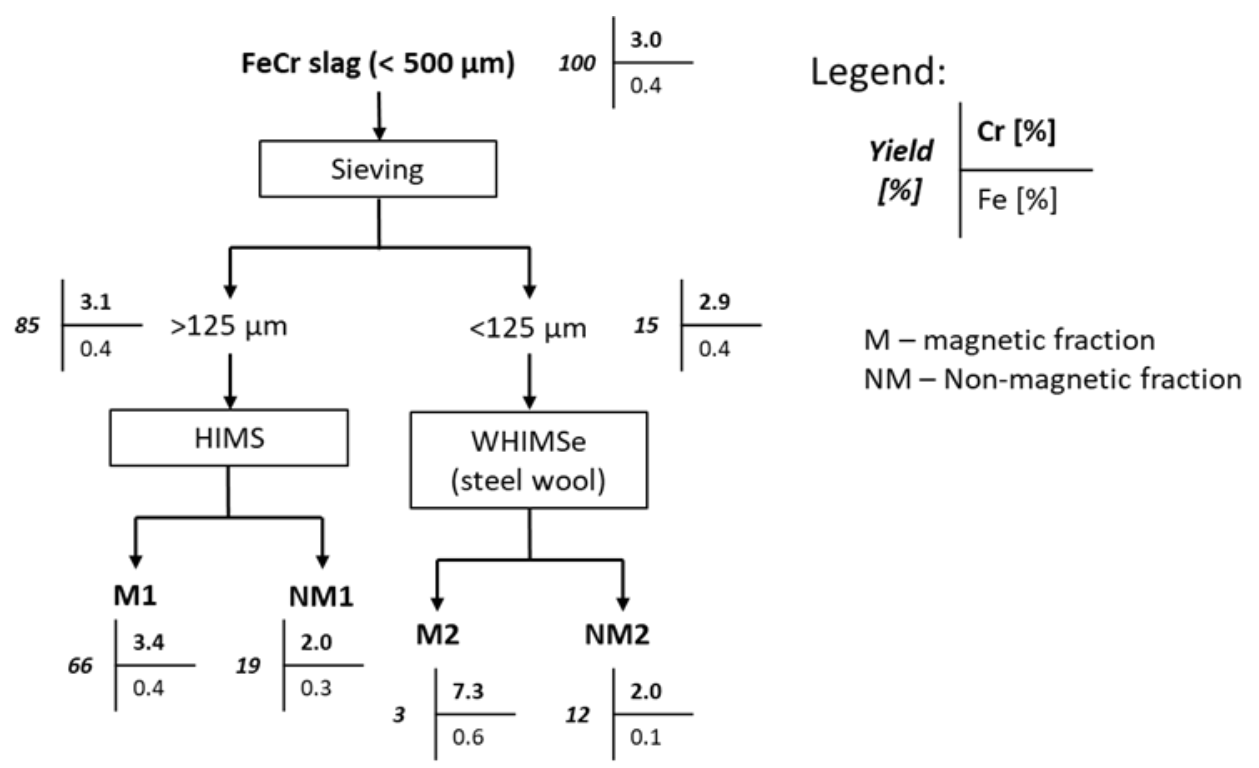

Figure 4. Processing flowsheet for LC FeCr slag.

As shown in Figure 4, the $<500 \mu \mathrm{m}$ fraction was first sieved into $<125 \mu \mathrm{m}$ and $>125 \mu \mathrm{m}$ fractions, which were treated by different techniques (dry vs. wet). Generally, in case of coarse particles $(>75 \mu \mathrm{m})$ both dry or wet magnetic separation can be used, while in case of fine particles $(<75 \mu \mathrm{m})$ wet magnetic separation is more appropriate [18]. HIMS was used to treat the fraction $>125 \mu \mathrm{m}$ while single WHIMSe (at $17.5 \mathrm{~A}$ ) was used for treating the fraction $<125 \mu \mathrm{m}$.

The difference in Cr content before and after HIMS separation ( $3.1 \mathrm{wt} . \%$ vs $3.4 \mathrm{wt} . \%$ ) was too small to justify the separation. On the other hand, treating the fraction $<125 \mu \mathrm{m}$ by WHIMSe shows a more significant $\mathrm{Cr}$ up-concentration in the magnetic fraction (M2) (7.3 wt.\% vs. $2.9 \mathrm{wt} . \%)$. This might be explained by a better liberation of the $\mathrm{Cr}$-rich phases in the fraction $<125 \mu \mathrm{m}$ as shown by SEM-EDS analysis (Figure 1b). However, the weight yield of fraction M2 was only 3\%, representing only $7 \%$ Cr recovery.

Figure 5 shows the results of sequential WHIMSe on LC FeCr slag $<125 \mathrm{~mm}$ with decreasing electric current. The fraction with the highest $\mathrm{Cr}$ content $(11 \mathrm{wt} . \%)$ was obtained after washing at $5 \mathrm{~A}$. The weight yield and $\mathrm{Cr}$ recovery were $3 \%$ and $14 \%$, respectively.

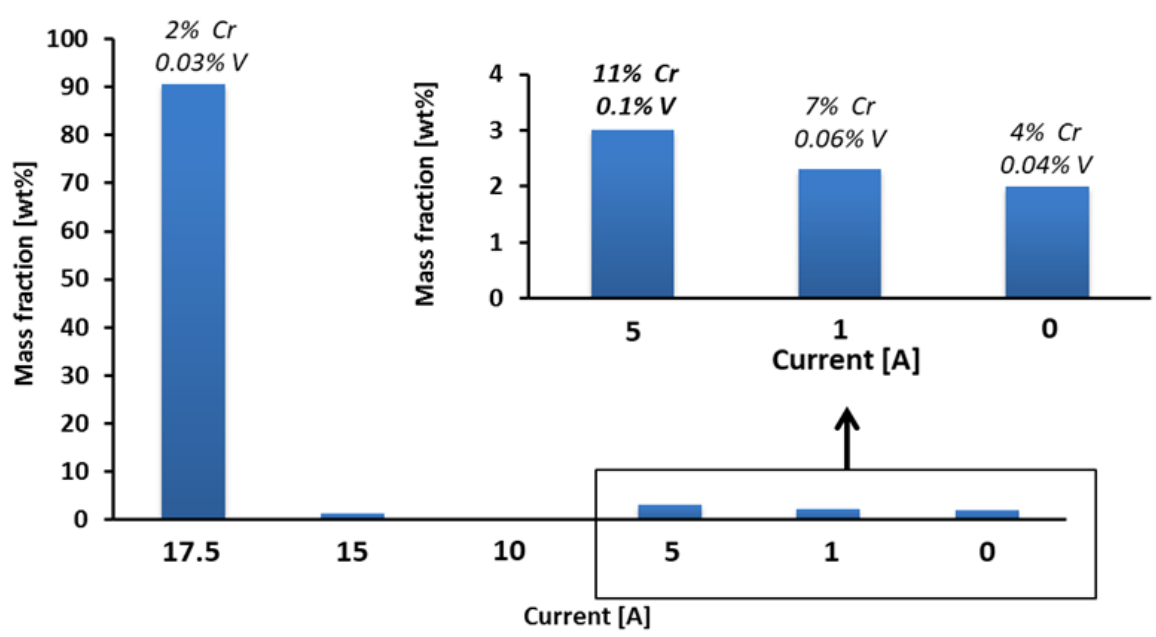

Figure 5. Results of sequential WHIMSe separation for LC FeCr slag-fraction $<125 \mu \mathrm{m}$.

Based on the results shown in Figures 4 and 5, it can be concluded that to up-concentrate $\mathrm{Cr}$ present in $\mathrm{LC} \mathrm{FeCr} \mathrm{slag} \mathrm{by} \mathrm{magnetic} \mathrm{separation} \mathrm{requires} \mathrm{an} \mathrm{additional} \mathrm{milling} \mathrm{step} \mathrm{to} \mathrm{liberate} \mathrm{Cr}$-rich 
particles from the matrix. However, considering the very low yield and $\mathrm{Cr}$ recovery, the economic feasibility of using a magnetic separation for LC FeCr slag is questionable.

\subsubsection{Magnetic Separation-HC FeCr Slag}

A combination of low and high intensity magnetic separation techniques was used to separate a Cr-rich phase from a Si-rich matrix. As observed in the SEM images (Figure 1c), relatively large fully liberated $\mathrm{FeCr}$ particles of around $500 \mu \mathrm{m}$ diameter, can be found in the $\mathrm{HC} \mathrm{FeCr}$ slag. For this reason, magnetic separation tests were performed on a wide range of particle sizes (from $<125 \mu \mathrm{m}$ to $>2 \mathrm{~mm}$ ). Depending on the particle size either dry or wet magnetic separation techniques were used. The fractions $>500 \mu \mathrm{m}$ were separated by dry magnetic separation and the fractions $<500 \mu \mathrm{m}$ by wet magnetic separation techniques. Figure 6 shows the separation process with three final output fractions.

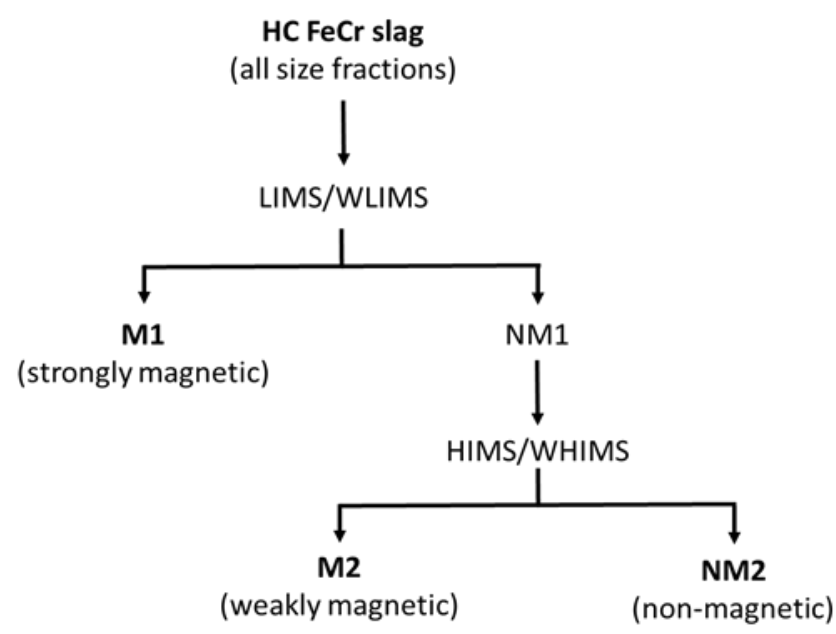

Figure 6. Combination of low and high intensity magnetic separation used for HC FeCr slag. (LIMS and HIMS for fractions $>500 \mu \mathrm{m}$ and WLIMS and WHIMS for fractions $<500 \mu \mathrm{m}$ ).

Before magnetic separation, the material was split into different size fractions. Chemical analysis of all size fractions (Table 4) clearly showed that $\mathrm{Cr}$ tends to concentrate in the smallest size fractions $(<125 \mu \mathrm{m}$ and $125-250 \mu \mathrm{m})$. As $\mathrm{Cr}$ is mostly present as a FeCr alloy, the Fe content follows the same trend.

Table 4. Chemical composition of different size fractions after sieving (HC FeCr slag).

\begin{tabular}{ccccccc}
\hline \multirow{2}{*}{ Fraction } & \multirow{2}{*}{ Yield (wt.\%) } & \multicolumn{5}{c}{ Content (wt.\%) } \\
\cline { 3 - 7 } & & Fe & Cr & Ca & Al & Si \\
\hline $2-4 \mathrm{~mm}$ & 10.9 & 6.8 & 8.7 & 1.8 & 10.9 & 13.7 \\
$1-2 \mathrm{~mm}$ & 20.4 & 5.2 & 10.1 & 1.9 & 9.9 & 13.8 \\
$0.5-1 \mathrm{~mm}$ & 25.5 & 5.0 & 9.4 & 1.9 & 9.5 & 13.3 \\
$250-500 \mu \mathrm{m}$ & 17.9 & 5.9 & 10.7 & 1.9 & 9.8 & 13.8 \\
$125-250 \mu \mathrm{m}$ & 14.8 & 8.8 & 14.8 & 1.7 & 10.5 & 13.6 \\
$<125 \mu \mathrm{m}$ & 10.1 & 10.9 & 16.8 & 1.8 & 11.2 & 12.8 \\
\hline Total & 100 & 6.5 & 11.2 & 1.8 & 10.1 & 13.5 \\
\hline
\end{tabular}

All size fractions were subjected to the magnetic separation according to Figure 6. As shown in Figure 7, the amount of the strongly magnetic fraction (M1) increased with decreasing particle size indicating that $\mathrm{FeCr}$ particles are mainly present as particles smaller than $250 \mu \mathrm{m}$. 


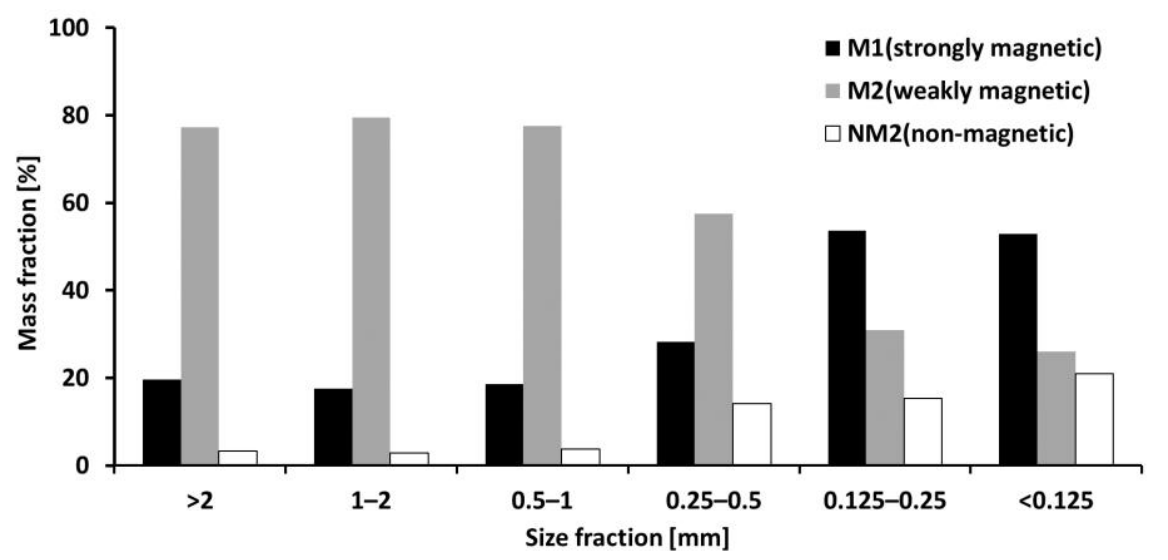

Figure 7. Mass balance after separation for all size fractions of $\mathrm{HC} \mathrm{FeCr} \mathrm{slag.}$

Figure 8 clearly shows that $\mathrm{Cr}$ is concentrated in the $\mathrm{M} 1$ fraction up to a level comparable with $\mathrm{Cr}$ ores of different grades (dashed lines in Figure 8). As expected, Fe also tends to concentrate in the M1 fractions (Supplementary Materials, Figure S4) while Si concentrates more in the non-magnetic (NM2) fractions (Supplementary Materials, Figure S5).

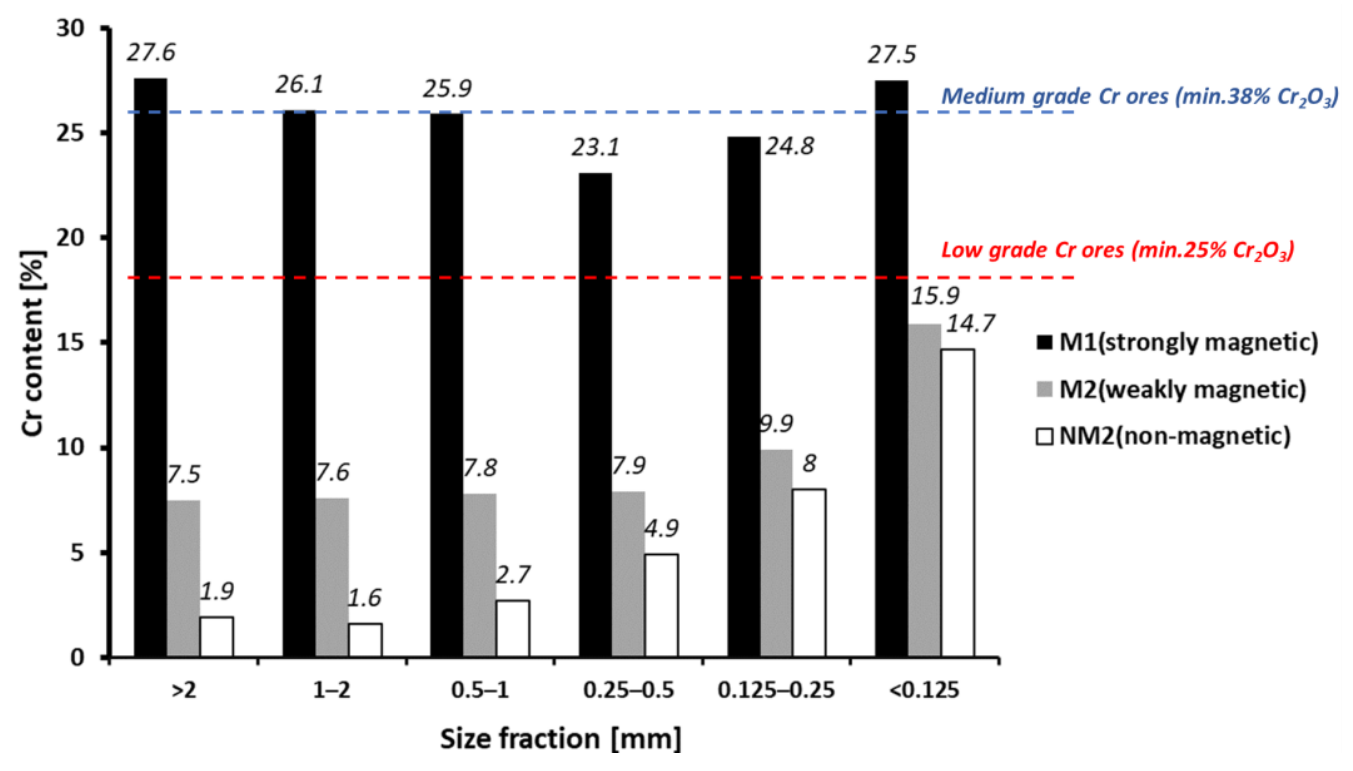

Figure 8. Cr content after magnetic separation of $\mathrm{HC}$ FeCr slag ( $\mathrm{Cr}$ ores grades according to [13]).

The final recoveries of $\mathrm{Cr}$ and $\mathrm{Fe}$ are shown in Figure 9. The highest recoveries of $\mathrm{Cr}$ and $\mathrm{Fe}(76 \%$ and $86 \%$ ) were obtained for size fraction $125-250 \mu \mathrm{m}$. This is mainly due to the better liberation of $\mathrm{Cr}$ (and Fe) rich phases. A slightly lower recovery for the fraction $<125 \mu \mathrm{m}$ can be caused by the presence of very fine particles, which are difficult to separate even by wet magnetic separation. 


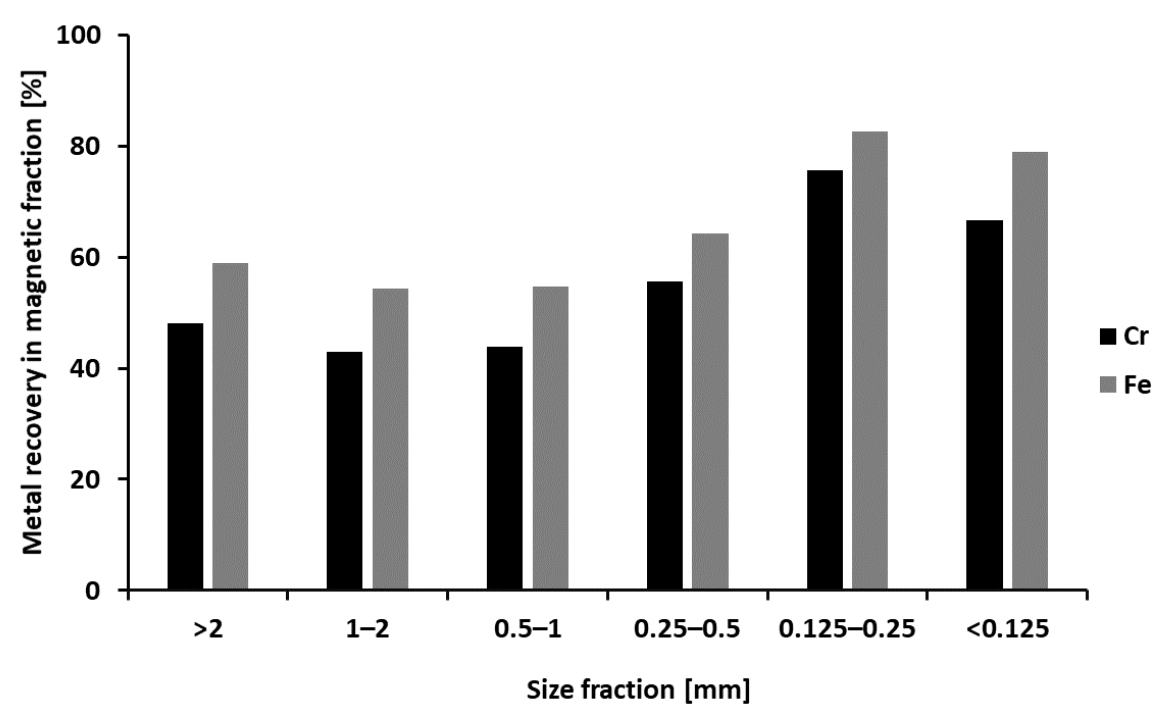

Figure 9. Recovery of $\mathrm{Cr}$ and Fe after magnetic separation of $\mathrm{HC}$ FeCr slag in M1 fraction.

\subsection{Results of Gravity Separation}

\section{Gravity Separation-HC FeCr Slag}

Five fractions (Supplementary Materials, Figure S6) were obtained after the gravity separation of HC FeCr slag (size fraction 1-2 mm) using a wet shaking table (WST). The mass balance of the output fractions is shown in Figure 10. After separation, all fractions were dried $\left(24 \mathrm{~h}\right.$ at $\left.40^{\circ} \mathrm{C}\right)$ and milled below $<125 \mu \mathrm{m}$ for XRF analysis. Results of XRF analysis are shown in Figure 11. Due to the very small amounts and visual similarity between fractions 4 and 5, these two fractions were combined and analyzed as one fraction.

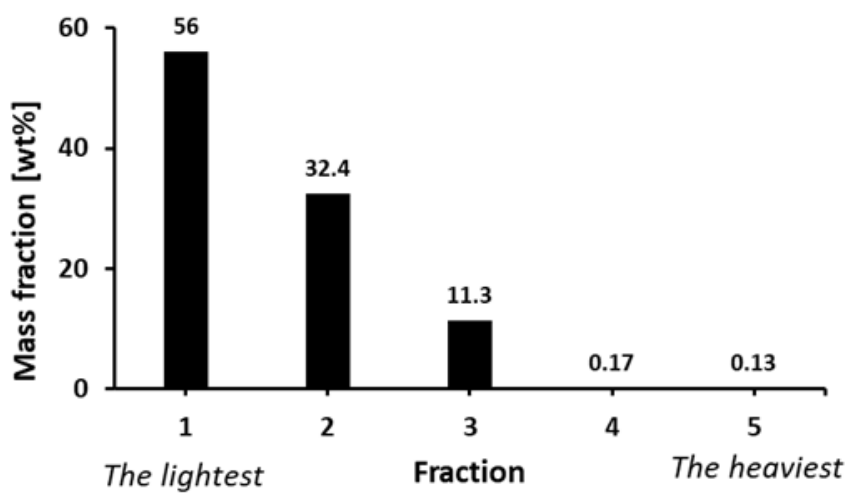

Figure 10. Mass balance after WST separation of HC FeCr slag (fraction 1-2 mm).

The combined fraction $(4+5)$ contains more than $38 \mathrm{wt} . \% \mathrm{Cr}$ and has a $\mathrm{Cr}$ content comparable with high grade $\mathrm{Cr}$ ores. However, this fraction represents only $0.3 \mathrm{wt} . \%$ of the initial material. By further combining with fraction 3, the $\mathrm{Cr}$ content of the combined sample would stay high ( $>32 \mathrm{wt} . \% \mathrm{Cr}$ ) and the weight yield would increase to almost $12 \mathrm{wt} . \%$, representing $36 \% \mathrm{Cr}$ recovery. This material could possibly be used as a replacement for primary high grade $\mathrm{Cr}$ ores in $\mathrm{FeCr}$ production plants. 


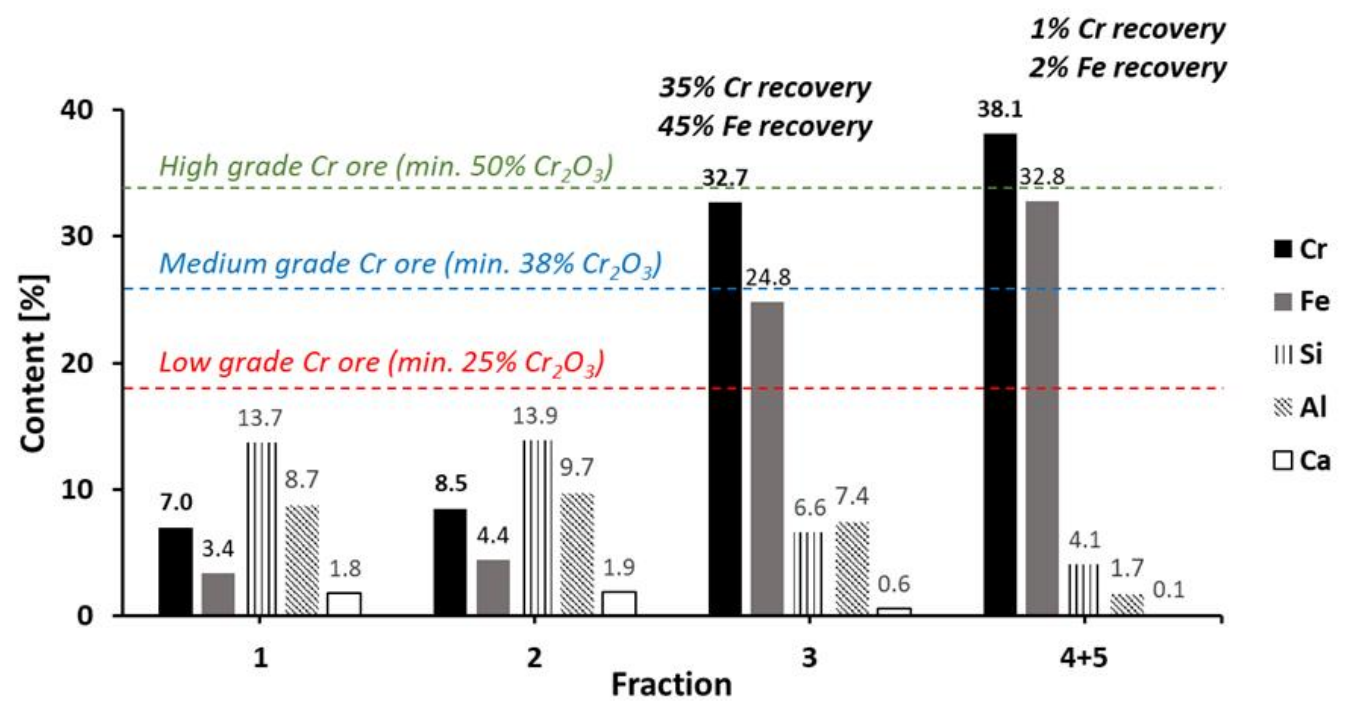

Figure 11. Content of metals in different fractions after WST (Cr ores grades according to [13]).

\section{Discussion}

By using magnetic separation, the $\mathrm{Cr}$ content of SS slags can be increased fourfold up to 8.8 wt.\% with $31 \%$ Cr recovery. While the obtained concentrations are too low to recover $\mathrm{Cr}$ by traditional pyrometallurgical processes, the up-concentration can be beneficial for the application in alternative hydrometallurgical processes. Such processes can be based on heap leaching [19], alkaline pressure leaching or alkaline roasting followed by water leaching where after selective $\mathrm{Cr}$ removal, the $\mathrm{Cr}$-depleted matrix can be used as a construction material $[20,21]$. As the capacity of hydrometallurgical facilities (especially those working at hydrothermal conditions) are often limited, reducing the amount of material to treat by preparing an up-concentrated fraction prior to the leaching step can be beneficial.

The $\mathrm{Cr}$ content in $\mathrm{LC}$ FeCr slag can be increased from $3 \%$ up to $11 \%$ by sequential WHIMSe separation. However, in this case the weight yield (3 wt.\%) and total $\mathrm{Cr}$ recovery $(14 \%)$ are relatively low. Moreover, to achieve such $\mathrm{Cr}$ up-concentration, the slag needs to be milled down to $<125 \mu \mathrm{m}$, what incurs additional costs. Considering the facts above, the economic feasibility of processing this LC FeCr slag by magnetic separation is questionable.

$\mathrm{Cr}$ content in $\mathrm{HC} \mathrm{FeCr} \mathrm{slag} \mathrm{can} \mathrm{be} \mathrm{increased} \mathrm{by} \mathrm{single} \mathrm{step} \mathrm{LIMS/WLIMS} \mathrm{to} \mathrm{the} \mathrm{level} \mathrm{comparable}$ with medium grade ores. This can be achieved due to the presence of well liberated Cr-rich grains in the initial material (as shown by SEM in Figure 1c). XRD analysis of the up-concentrated magnetic fraction (Figure 12) showed that except of $\mathrm{Cr}$-spinels also metallic Fe-Cr particles can be clearly identified. However, $\mathrm{Cr}$ content in up-concentrated magnetic fractions was still below the typical requirements ( $>49 \% \mathrm{Cr}_{2} \mathrm{O}_{3}$ ) for using it as input material for smelting of $\mathrm{FeCr}$. Additional $\mathrm{Cr}$ up-concentration can be achieved, for instance, by combining magnetic and gravity separation and/or combining different gravity separation techniques in one process as demonstrated by Can et al. [22]. 


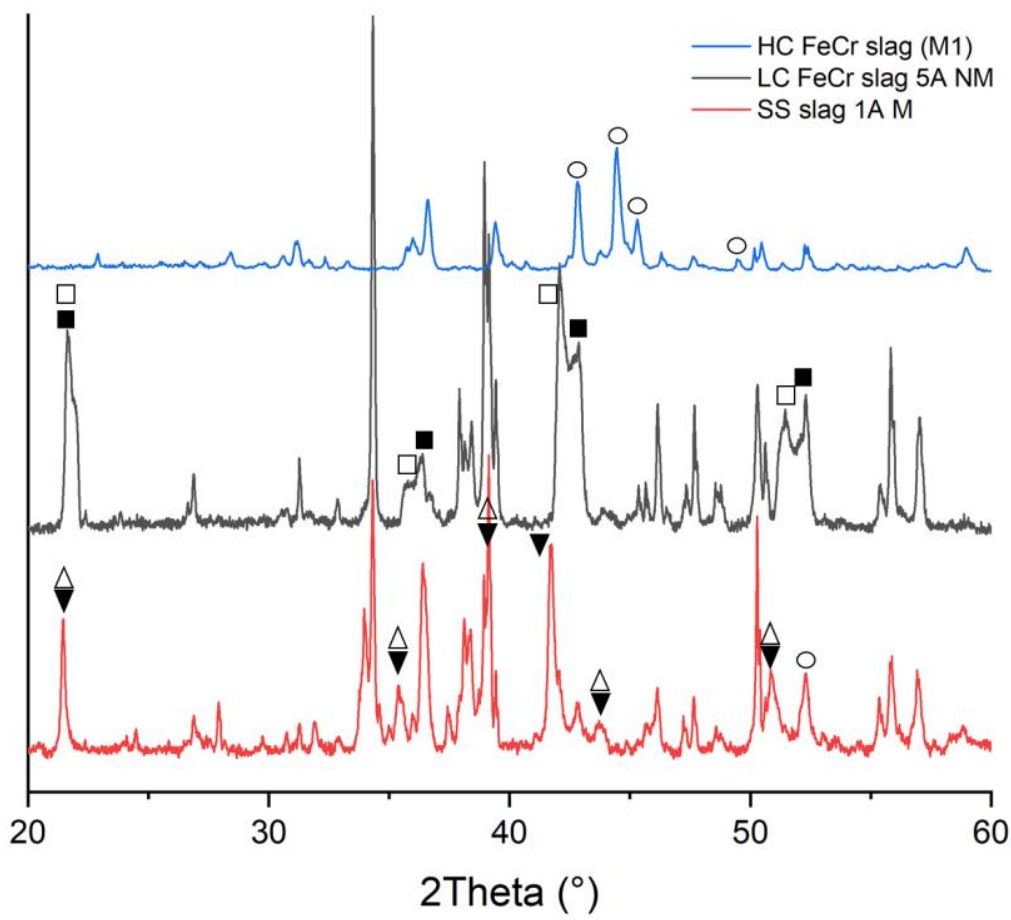

- Mg-Cr-Al spinel

$\square \mathrm{Mg}-\mathrm{Mn}-\mathrm{Cr}-\mathrm{Al}$ spinel

$\circ \mathrm{Fe}-\mathrm{Cr}$ alloy

$\triangle \mathrm{Mg}-\mathrm{Cr}-\mathrm{Fe}$ spinel

$\nabla$ Mg-Cr-Fe-Al spinel

Figure 12. XRD patterns showing Cr-phases in the most up-concentrated fractions of SS, LC FeCr, and $\mathrm{HC}$ FeCr slag (not identified peaks belong mostly to Ca-(Mg-Al-)silicates like merwinite, bredigite, and akermanite).

Although, SS slag and LC FeCr slag have very similar chemical and mineralogical compositions, there are significant differences in $\mathrm{Cr}$ up-concentration after magnetic separation. This can be explained by different $\mathrm{Cr}$-containing spinels present in both samples. As shown in Figure 12, in case of $\mathrm{LC} \mathrm{FeCr}$ slag, the $\mathrm{Cr}$ containing spinels were represented by $\mathrm{Mg}-\mathrm{Cr}-\mathrm{Al}$ and $\mathrm{Mg}-\mathrm{Mn}-\mathrm{Cr}-\mathrm{Al}$ spinels, while in $\mathrm{SS}$ slag it was mainly $\mathrm{Mg}-\mathrm{Cr}-\mathrm{Fe}$ and $\mathrm{Mg}-\mathrm{Cr}-\mathrm{Fe}-\mathrm{Al}$ spinels. Even though all those spinels have the same structure (cubic, space group Fd-3m) different metal cations present in the structure can be responsible for different magnetic susceptibility, and thus a slightly different behavior in a magnetic field. The presence of Fe in the Mg-Cr-Fe spinels, in case of SS slag, can explain why Cr was concentrated mostly in the most magnetic fraction while in case of $\mathrm{LC} \mathrm{FeCr}$ slag, the $\mathrm{Cr}$ rich fraction was obtained as a weak-magnetic fraction at 5A. As shown in Figure 13, compounds with spinel structure containing Fe in their lattice are more magnetic compared to those without Fe.

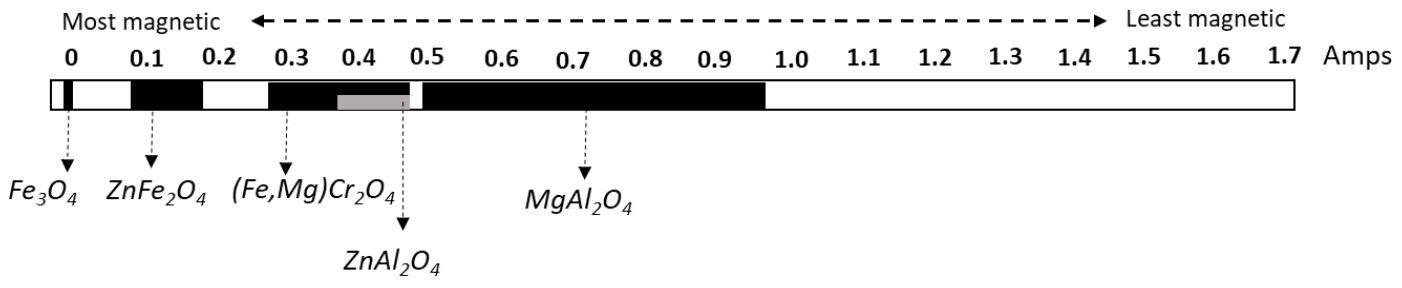

Figure 13. Magnetic properties of different spinel structures [23].

In case of gravity separation of $\mathrm{HC} \mathrm{FeCr}$ slag, the $\mathrm{Cr}$ content in the heaviest fractions can be increased by a factor of more than three to the level comparable with high grade ores, which might be used directly in $\mathrm{FeCr}$ production. Light fractions after gravity separation, containing 7.0 and $8.5 \mathrm{wt} . \% \mathrm{Cr}$, might be processed, in a similar way as the up-concentrated fraction of SS slags, i.e., by hydrometallurgical methods to selectively remove $\mathrm{Cr}$ and enable full valorization of the $\mathrm{Cr}$-depleted matrix in construction industry. 
In comparison with other studies (summarized in a review paper of Murphy et al. [14]), where the aim was to up-concentrate $\mathrm{Cr}$ in low grade ores by applying gravity and magnetic separation techniques, reported $\mathrm{Cr}$ up-concentrations were rarely above a factor of two. Moreover, in order to reach such up-concentrations, a combination of different separation techniques was used (e.g., shaking table and WHIMS). Results of our study clearly show that even one-step gravity separation of HC FeCr slag, can lead to $\mathrm{Cr}$ up-concentration by a factor of more than three to the level of high grade Cr ore, with $35 \%$ of $\mathrm{Cr}$ recovery. This is caused by the presence of metallic Fe-Cr particles (mainly in $\mathrm{HC}$ FeCr slag, as shown in Figure 12) which due to higher magnetic susceptibility and density can be separated from the matrix (mostly Ca-Mg-Al silicates) more easily. This proves, that $\mathrm{HC}$ FeCr slag can already be considered, after magnetic or gravity separation, as a replacement for medium or even high grade primary ores used in FeCr production. Reusing a part of FeCr slag back in FeCr production could help to accelerate the transition to a circular economy in FeCr industry.

\section{Conclusions}

Magnetic and gravity separation techniques were investigated in order to up-concentrate $\mathrm{Cr}$ in Cr-containing slags coming from SS and FeCr productions. Results of this study clearly show potential for applying of these beneficiation methods in processing SS and HC FeCr slags.

In case of SS slag, Cr up-concentration up to almost 9 wt.\% can be obtained by WHIMS. As this $\mathrm{Cr}$ content is still low for FeCr production, this can be considered as a pre-treatment step prior to hydrometallurgical $\mathrm{Cr}$ recovery. Although, similar $\mathrm{Cr}$ up-concentration by using WHIMSe was obtained also in case of LC FeCr slag, in this case due to required milling and low yield (3 wt.\%) such treatment would not be economically feasible. In case of HC FeCr slag, both magnetic and gravity separation resulted in an up-concentrated fraction with a $\mathrm{Cr}$ content comparable with commercial primary Cr ores. Especially, when gravity separation by wet shaking table was applied on 1-2 mm HC FeCr slag, material comparable with high grade $\mathrm{Cr}$ ores was obtained.

Supplementary Materials: The following are available online at http://www.mdpi.com/2075-163X/10/10/906/s1, Figure S1: Magnetic separation equipment used: (a) LIMS/HIMS, (b) WLIMS/WHIMS, and (c) WHIMSe.; Figure S2: Relation between current (in Amperes) and magnetic field (in Gauss) - provided by the equipment manufacturer Master Magnets Ltd.; Figure S3: The WST (wet shaking table) with the indication of the output fractions.; Figure S4: Fe content after magnetic separation of HC FeCr slag.; Figure S5: Si content after magnetic separation of HC FeCr slag. Figure S6: Output fractions after WST separation of HC FeCr slag (fraction 1-2 mm).

Author Contributions: Conceptualization, F.K. and P.N.; writing—original draft preparation, F.K.; writing一review and editing, F.K., P.N., and L.H.; funding acquisition, L.H. All authors have read and agreed to the published version of the manuscript.

Funding: This research was funded by the European Union's Horizon 2020 Research and Innovation program under Grant Agreement no 730471.

Conflicts of Interest: The authors declare no conflict of interest. The funders had no role in the design of the study; in the collection, analyses, or interpretation of data; in the writing of the manuscript, or in the decision to publish the results.

\section{References}

1. International Stainless Steel Forum (ISSF) Shanghai, Stainless Steel in Figures 2018. 2018. Available online: http://www.worldstainless.org/Files/issf/non-imagefiles/PDF/ISSF_Stainless_Steel_in_Figures_2018_ English_Public.pdf (accessed on 24 June 2020).

2. Salman, M.; Dubois, M.; Di Maria, A.; Van Acker, K.; Van Balen, K. Construction Materials from Stainless Steel Slags: Technical Aspects, Environmental Benefits, and Economic Opportunities. J. Ind. Ecol. 2016, 20, 854-866. [CrossRef]

3. Horckmans, L.; Möckel, R.; Nielsen, P.; Kukurugya, F.; Vanhoof, C.; Morillon, A.; Algermissen, D. Multi-Analytical Characterization of Slags to Determine the Chromium Concentration for a Possible Re-Extraction. Minerals 2019, 9, 646. [CrossRef] 
4. Euroslag, Statistics 2016. Available online: https://www.euroslag.com/wp-content/uploads/2019/01/Statistics2016.pdf (accessed on 24 June 2020).

5. Karhu, M.; Talling, B.; Piotrowska, P.; Matas Adams, A.; Sengottuvelan, A.; Huttunen-Saarivirta, E.; Boccaccini, A.R.; Lintunen, P. Ferrochrome Slag Feasibility as a Raw Material in Refractories: Evaluation of Thermo-physical and High Temperature Mechanical Properties. Waste Biomass Valorizat. 2020. [CrossRef]

6. Mombelli, D.; Mapelli, C.; Barella, S.; Di Cecca, C.; Le Saout, G.; Garcia-Diaz, E. The effect of chemical composition on the leaching behaviour of electric arc furnace (EAF) carbon steel slag during a standard leaching test. J. Environ. Chem. Eng. 2016, 4, 1050-1060. [CrossRef]

7. Zhao, Q.; Liu, C.; Cao, L.; Zheng, X.; Jiang, M. Stability of chromium in stainless steel slag during cooling. Minerals 2018, 8, 445. [CrossRef]

8. Kotas, J.; Stasicka, Z. Chromium occurence in the environment and methods of its speciation. Environ. Pollut. 2000, 107, 263-283. [CrossRef]

9. Cheremisina, E.; Schenk, J. Chromium Stability in Steel Slags. Steel Res. Int. 2017, 87, 1-7. [CrossRef]

10. European Commission, Critical Raw Materials. Available online: https://ec.europa.eu/growth/sectors/rawmaterials/specific-interest/critical_en (accessed on 30 June 2020).

11. Seuker, J. Chromium. In Environmental Forensics: Contaminant Specific Guide; Morrison, R.D., Murphy, B., Eds.; Elsevier Inc.: Amsterdam, The Netherlands, 2006; pp. 81-93.

12. Gianluca, C.; Rodrigo Gonzalo, M.; Farrell, F.; Roudier, S.; Remus, R.; Delgado Sancho, L. Best Available Techniques (BAT) Reference Document for the Main Non-Ferrous Metals Industries; European Commission: Brussels, Belgium, 2017. [CrossRef]

13. Gasik, M.I. Technology of Chromium and Its Ferroalloys. Handb. Ferroalloys 2013. [CrossRef]

14. Murthy, Y.R.; Tripathy, S.K.; Kumar, C.R. Chrome ore benefication challenges \& opportunities-A review. Miner. Eng. 2011, 24, 375-380.

15. Tripathy, S.K.; Banerjee, P.K.; Suresh, N. Magnetic separation studies on ferruginous chromite fine to enhance Cr:Fe ratio. Int. J. Miner. Metall. Mater. 2015, 22, 217-224. [CrossRef]

16. Tripathy, S.K.; Singh, V.; Ramamurthy, Y. Improvement in Cr:Fe Ratio of Indian Chromite Ore for Ferro Chrome Production. Int. J. Min. Eng. Miner. Process. 2012, 1, 101-106. [CrossRef]

17. Tripathy, S.K.; Murthy, Y.R.; Singh, V.; Suresh, N. Processing of ferruginous chromite ore by dry high-intensity magnetic separation. Miner. Process. Extr. Metall. Rev. 2016, 37, 196-210. [CrossRef]

18. Svoboda, J. Magnetic Techniques for the Treatment of Materials; Kluwer Academic Publishers: Dordrecht, The Netherlands, 2004.

19. Spooren, J.; Kim, E.; Horckmans, L.; Broos, K.; Nielsen, P.; Quaghebeur, M. In-situ chromium and vanadium recovery of landfilled ferrochromium and stainless steel slags. Chem. Eng. J. 2016, 303, 359-368. [CrossRef]

20. Kim, E.; Spooren, J.; Broos, K.; Nielsen, P.; Horckmans, L.; Geurts, R.; Vrancken, K.C.; Quaghebeur, M. Valorization of stainless steel slag by selective chromium recovery and subsequent carbonation of the matrix material. J. Clean. Prod. 2016, 117, 221-228. [CrossRef]

21. Gu, F.; Zhang, Y.; Peng, Z.; Su, Z.; Tang, H.; Tian, W.; Liang, G.; Lee, J.; Rao, M.; Li, G.; et al. Selective recovery of chromium from ferronickel slag via alkaline roasting followed by water leaching. J. Hazard. Mater. 2019, 374, 83-91. [CrossRef] [PubMed]

22. Can, İ.B.; Özsoy, B.; Ergün, Ş.L. Developing an optimum beneficiation route for a low-grade chromite ore. Physicochem. Probl. Miner. Process. 2019. [CrossRef]

23. USA Geological Survey, Magnetic Susceptibilities of Minerals, Reston, VA. 2000. Available online: https: //doi.org/10.3133/ofr99529 (accessed on 24 June 2020).

(C) 2020 by the authors. Licensee MDPI, Basel, Switzerland. This article is an open access article distributed under the terms and conditions of the Creative Commons Attribution (CC BY) license (http://creativecommons.org/licenses/by/4.0/). 